\title{
Sustainability Assessment for Dry, Conventional and Cryogenic Machining in Face Milling of Ti-6Al-4V
}

\author{
IMRAN MASOOD*, MIRZA JAHANZAIB*, AND AHMAD WASIM* \\ RECEIVED ON 11.12.2015 ACCEPTED ON 11.05.2016
}

\begin{abstract}
Sustainability achievement in difficult-to-machine materials is major concern now-a-days. This paper presents sustainability assessment of machining titanium alloy Ti-6Al-4V. Face milling of Ti-6Al-4V hardened to 55 HRC with PVD (Physical Vapour Deposition) coated inserts was analyzed for dry, conventional and cryogenic cooling modes. Experiments were designed using CCD (Central Composite Design) for modeling and analysis of surface roughness. Feed, speed and depth of cut were used as input parameters. For a specific surface finish, the three cooling modes were compared for cutting power, machining time and material removal rate. The results indicate that cryogenic cooling was more sustainable as compared to dry and conventional cooling process. This sustainable model will help to select sustainable input parameters.
\end{abstract}

Key Words: Cryogenic Cooling, Face Milling, Sustainable Machining.

\section{INTRODUCTION}

$\Gamma$

The Production Industries are facing economic pressure and therefore trying to compensate the increasing costs and creating value addition in their products. Sustainable manufacturing in production improves the environmental and economic conditions.

In sustainable machining, parts are manufactured through economically sound processes along with negative impact on environment conserving natural resources and energy. Sustainability principles in machining are worldwide useful in order to save money and enhancement of environmental performance. Energy, economic growth, environmental effects, waste reduction, personnel health and social norms are addressed simultaneously in sustainability.
In recent years attention has been made on achieving comprehensive strategy over sustainable manufacturing due to increased emission of $\mathrm{CO}_{2}$ in environment and waste. This will ultimately improve the industry's economy [1].

The combination of environmental protection with the economical growth in production on practical level yields promotion for sustainable manufacturing resulting environmental improvement along with social performance, product, processes and protection against threats to health.

For implementation of sustainability, the objectives may be set and environmental/health aspect be used in limited capacity and focusing on more cost saving. Machining

* Department of Industrial Engineering, University of Engineering \& Technology, Taxila.

Mehran University Research Journal of Engineering \& Technology, Volume 36, No. 2, April, 2017 [p-ISSN: 0254-7821, e-ISSN: 2413-7219] 
technology is referring to implement the sustainability which has potential to improve environmental performance and save money. The problem in implementing sustainability in Production companies is due to short-term financial planning. However, long-term strategy is necessary for sustainable manufacturing.

The initiatives for the sustainable development are established at different levels e.g. UN, OECD, National Level and are well positioned on macro level of production [2] but are lacking in implementation at shop floor level.

\section{LITERATURE REVIEW}

In the process of transforming inputs to outputs, the consumption of resources is reduced to achieve sustainability. Refining the processes and machine tools are major factors for reducing the resources and energy consumption. The production systems are designed to support the continuous waste reduction, elimination or recycling. This can be achieved by less generation of waste, increasing recycling or re-usage, efficient usage of water, materials, energy, avoiding metal working fluids and improving the management of lubricating oils, swarf and hydraulics oils.

Machining process contributes to worldwide economy and is about $5 \%$ of the total GDP [3]. It tends to become unsustainable when using such CLF (Cooling and Lubrication Fluids) which are oil based. These are made from mineral oils extracted from crude oil which is highly non-sustainable. Extract of crude oil is used to formulate the mineral oil which is converted to CLF. Although the vegetable oils are naturally derived but these are not used as CLF due to higher costs and reduced performance [4].

Vegetable based oils are costly and give reduced performance in some applications therefore are seldom used. The toxicity of such oils is less as compared with mineral oil based coolants and found good for working in suitable conditions. Problems of health and environment are connected with the CLF and its cleaning process is also a time consuming and costly.

Higher temperatures are observed in the HSM (HighSpeed Machining) that result high temperatures at cutting tool and part interface. Development in the coolants and lubrication techniques has a lot of gap for researchers to find the best cooling technique. Conventional CLF are widely being used in metal cutting industry to counter the heat generated by machining besides that they have disadvantage of hazardous to health and environment. Cutting Tool cost in machining operation is about $4 \%$ of total machining cost whereas $15 \%$ of total machining cost is due to use of CLF emulsions [5]. Machining of Titanium bears more cost as compared with other common materials along with pollution effect of machining on environment as shown in Fig. 1.

Sustainability will be gained by using the alternatives of CLF and dry machining using the coated cutting tools [7]. Dry machining is not recommended at high speed machining of difficult-to-machine materials. Such materials are used in aerospace industry and are capable of bearing high operational temperature like in jet engines. Most commonly used materials in aerospace industry are Nickel alloys, Titanium alloys and $\mathrm{Co}-\mathrm{Cr}$ alloys [8-9]. Thermal conductivity of such materials is low and therefore temperature observed at the cutting zone is extremely

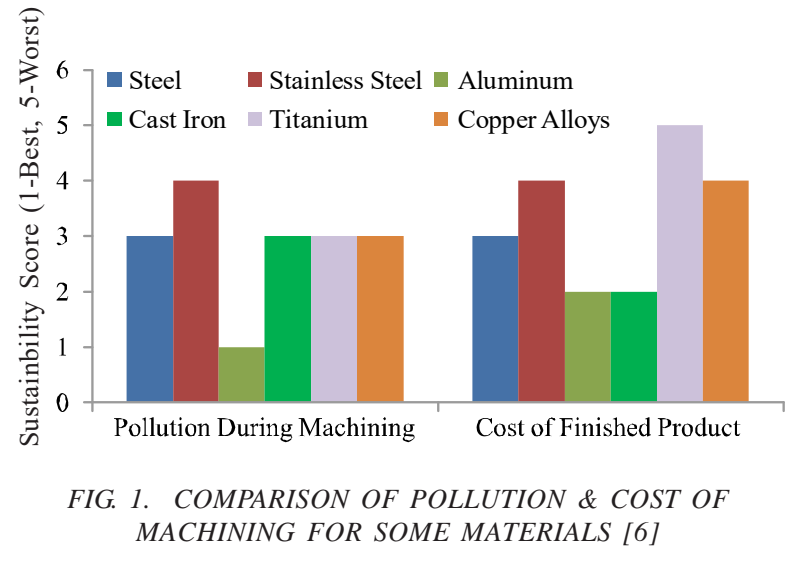

Mehran University Research Journal of Engineering \& Technology, Volume 36, No. 2, April, 2017 [p-ISSN: 0254-7821, e-ISSN: 2413-7219] 
high. These facts have called for sustainability in machining and finding the alternate to conventional oilbased CLF as cooling and lubrication [10-13]. In machining of hard and difficult to machine materials the conventional CLF (Oil-based) do not effectively decrease the cutting temperatures and therefore tool life is not increased. It is due to the fact that the coolants do not access the chiptool interface which is under high cutting temperature and vaporizes close to the cutting edge. Due to this phenomenon the conventional CLF becomes ineffective for machining the materials with low thermal conductivity and high shear strength.

The technique of machining called NDM (Near to Dry Machining) is helpful in sustainable machining to ensure safe for environment, for the workers [14] and it is economically cost saving [15]. The tool life is enhanced with decrease in its wear and improvement in surface finish is observed using MQL (Minimal Quantity Lubrication) technique of lubrication as compared to the cutting with flood condition or dry cutting [16]. Present investigations show that the cutting fluids are creating severe problems to health and environment [17]. The conventional fluids are considered very dangerous to the health and are rated out of top five hazardous to health [18].

Cryogenic machining is much safer than the conventional lubrication and coolants. Nitrogen gas has no hazards on life as about $79 \%$ of this already exist in air. Nitrogen at cooling temperature is effective for cooling the cutting edge during machining of hard materials as cutting temperature exceeds $200^{\circ} \mathrm{C}$. It is a new technique of cooling the cutting zone and part during the machining at high speed and temperatures with cryogenic CLF. The coolant is Nitrogen which is liquefied at $-196^{\circ} \mathrm{C}$ and is safe, non-corrosive and non-combustible gas. This gas evaporates leaving no contaminates with part, operator, machine tool, chips thus disposal cost is eliminated. Mostly cryogenic CLF are applied in the machining of super alloys.
The cryogenic machining process is more beneficial as more sustainable in terms of safety, Clean and environment friendly machining. Due to minimization in changeover time, productivity also increases. Tool life is increased due to low abrasion rate and chemical wear. Improvement is observed in the surface quality without the degradation in its mechanical/chemical properties.

Application of cryogenic machining at shop floor level will be transitioning towards the sustainable machining and will promote the development of optimization for cryogenic fluid delivery with mass flow and controlled pressure.

In cryogenic machining the cryogenic fluid is directly applied on the cutting tip of the tool. This flow is manageable to be controlled against flow and pressure which makes it more economic than conventional fluids. $\mathrm{N}_{2}$ gas is used as cooling medium in cryogenic machining and is harmless to the health. This process increases the tool life and helps in productivity improvement, surface integrity improvement, chip breakability enhancement, reduction in built-up-edge and burr formation [19-22]. One of the disadvantages for cryogenic machining is that the liquid Nitrogen is comparatively costly which is not reusable like the Conventional CLF also additional equipment is required for it.

In comparison of cryogenic cooling with conventional cooling and lubrication process it is clear that the cost of power required for pumping of cooling and lubrication fluid is eliminated. Cost of cleaning CLF from the machined part becomes zero.

The objective of this research is to analyze the effect of cryogenic cooling over surface finish of Titanium alloy. In aerospace industry parts are mostly machined after heat treatment of raw material. Face milling is one of the most common processes performed over the super alloys. A fine surface machined part bears good characteristics. 


\section{EXPERIMENTAL DETAIL}

Face milling of Titanium alloy Ti-6Al-4V is performed to check the surface finish using dry machining, conventional machining and cryogenic machining. Chemical analysis of Titanium alloy was first performed using the XRF (XRay Fluorescence) material analyzer and results are given in Table 1 and Fig. 2.

The surface hardness was checked using the "Universal Hardness Tester (CV Instruments)" and hardness found as $34 \mathrm{HRC}$ in annealed condition. Titanium alloy was hardened by heat treatment at $955^{\circ} \mathrm{C}$ for 12 hours. The process of heat treatment caused building of scaling layer over the metal which was removed using machining. Hardness tested after heat treatment and found 55 HRC.

Face milling done using end mill cutter (dia $20 \mathrm{~mm}$ ) with two inserts on DMU-50 CNC Milling machine using PVD coated carbide inserts "APTM 1135 PDER-M2 VP15TF". Cutting conditions were set as given in Table 2. Surface finish was checked using roughness tester Perthometer M2 with drive unit Mahr PGK-120.

\subsection{Dry Machining}

Experiments performed using recommended cutting conditions of cutting tool for face milling as given in Mitsubishi catalogue. Experimental model designed using software of Design Expert 7.0 and the technique of CCD (Central Composite Design) was selected (Fig. 3).

Five levels of each factor are selected to check the response of each variable over the surface finish (Table 2).
Using the software of Design Expert, different combinations of three variables were generated. Experiments were performed on basis of these combinations and the response surface finish was checked against each combination. Each input variable affects the output response for certain value. Table 3 and Fig. 4 describes the response of each combination of input variable factor.

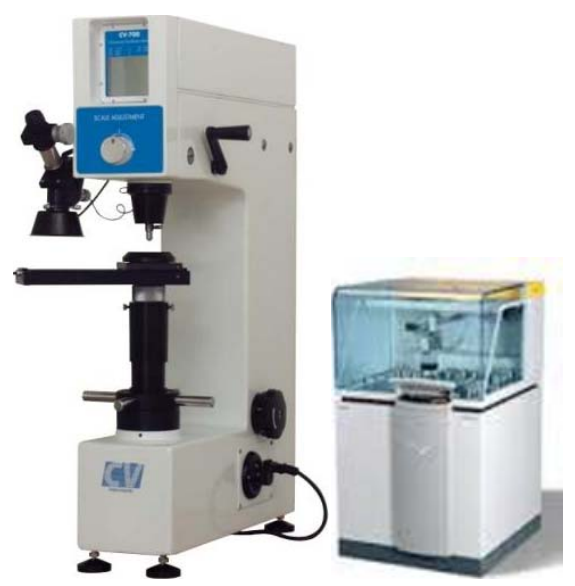

FIG. 2. HARDNESS TESTER AND XRF MATERIAL ANALYZER

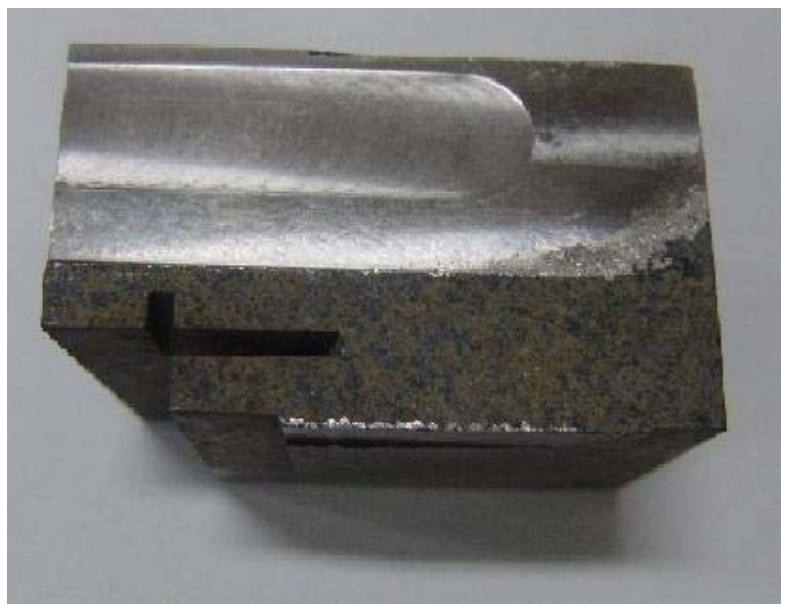

FIG. 3. HEAT TREATED WORK MATERIAL

TABLE 1. CHEMICAL COMPOSITION OF MATERIAL UNDER CONSIDERATION

\begin{tabular}{|c|c|c|c|c|c|c|c|}
\hline $\mathrm{Al}$ & $\mathrm{V}$ & $\mathrm{Fe}$ & $\mathrm{Mn}$ & $\mathrm{Be}$ & $\mathrm{Mg}$ & $\mathrm{Si}$ & $\mathrm{Ti}$ \\
\hline 5.776 & 3.893 & 0.17 & 0.012 & 0.25 & 0.022 & 0.034 & $\mathrm{Bal}$ \\
\hline
\end{tabular}

Mehran University Research Journal of Engineering \& Technology, Volume 36, No. 2, April, 2017 [p-ISSN: 0254-7821, e-ISSN: 2413-7219] 
Factors affecting the surface finish are in the order of Feed, DoC and cuttng speed as given by their P-values shown in Table 4. Change in feed will affect more than other parameters of speed and depth of cut (Table 4 and Fig. 5).

\subsection{Conventional and Cryogenic Machining}

The experiments were repeated using conventional lubricant (Shell Macron-b) cutting oil as coolant and the surface response was checked for each designed
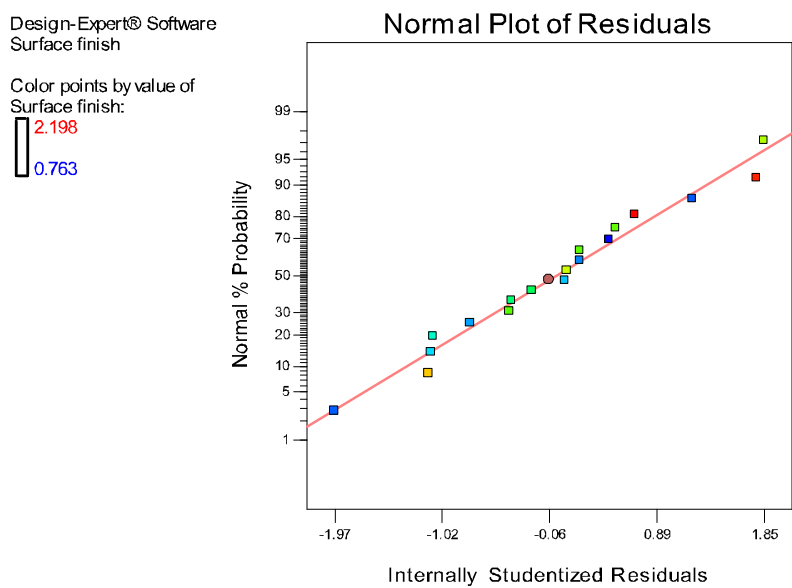

FIG. 4. NORMAL PROBABILITY PLOT OF RESIDUALS FOR $R_{a}$

TABLE 2. LEVELS OF INDEPENDENT VARIABLES

\begin{tabular}{|c|c|c|c|c|c|}
\hline Code & -1.6818 & -1 & 0 & 1 & 1.6818 \\
\hline Levels & Very Low & Low & Medium & High & Very High \\
\hline Cutting Speed $(\mathrm{m} / \mathrm{min})$ & 9.773 & 20.000 & 35.000 & 50.000 & 60.227 \\
\hline Feed (mm/tooth) & 0.066 & 0.100 & 0.150 & 0.200 & 0.234 \\
\hline Depth of Cut (mm) & 0.016 & 0.050 & 0.100 & 0.150 & 0.184 \\
\hline
\end{tabular}

TABLE 3. CUTTING PARAMETERS AND RESPONSE VALUES OF $R_{\mathrm{a}}$

\begin{tabular}{|c|c|c|c|c|c|}
\hline \multirow[b]{2}{*}{ Standard Order } & \multirow[b]{2}{*}{ Run \# } & \multicolumn{4}{|c|}{ Actual Parameters } \\
\hline & & $\begin{array}{l}\text { Cutting Speed } \\
(\mathrm{m} / \mathrm{min})\end{array}$ & $\begin{array}{c}\text { Feed } \\
\text { (mm/tooth) }\end{array}$ & $\begin{array}{l}\text { Depth of Cut } \\
\text { (mm) }\end{array}$ & $\begin{array}{c}\text { Surface finish } \\
\qquad(\mu \mathrm{m})\end{array}$ \\
\hline 1 & 11 & 20 & 0.1 & 0.050 & 0.89 \\
\hline 2 & 13 & 50 & 0.1 & 0.050 & 0.95 \\
\hline 3 & 7 & 20 & 0.2 & 0.050 & 1.62 \\
\hline 4 & 9 & 50 & 0.2 & 0.050 & 1.77 \\
\hline 5 & 15 & 20 & 0.1 & 0.150 & 1.043 \\
\hline 6 & 17 & 50 & 0.1 & 0.150 & 1.073 \\
\hline 7 & 1 & 20 & 0.2 & 0.150 & 2.151 \\
\hline 8 & 2 & 50 & 0.2 & 0.150 & 2.198 \\
\hline 9 & 5 & 9.773 & 0.15 & 0.100 & 0.894 \\
\hline 10 & 3 & 60.227 & 0.15 & 0.100 & 1.61 \\
\hline 11 & 10 & 35 & 0.066 & 0.100 & 0.763 \\
\hline 12 & 4 & 35 & 0.234 & 0.100 & 1.916 \\
\hline 13 & 12 & 35 & 0.15 & 0.016 & 0.991 \\
\hline 14 & 18 & 35 & 0.15 & 0.184 & 1.606 \\
\hline 15 & 14 & 35 & 0.15 & 0.100 & 1.727 \\
\hline 16 & 16 & 35 & 0.15 & 0.100 & 1.321 \\
\hline 17 & 6 & 35 & 0.15 & 0.100 & 1.354 \\
\hline 18 & 8 & 35 & 0.15 & 0.100 & 1.195 \\
\hline
\end{tabular}

Mehran University Research Journal of Engineering \& Technology, Volume 36, No. 2, April, 2017 [p-ISSN: 0254-7821, e-ISSN: 2413-7219] 
combination of feed, speed and depth of cut. It was found that the surface finish values in a combination of input variables for dry machining are close to other combinations for conventional machining. Later on experiments were repeated using $\mathrm{N}_{2}$ gas as coolant. Liquid Nitrogen stored in a cylinder was exposed in gaseous form to the interface of cutting tool cutting edge and the material. Both dry and conventional machining were compared against the same output of surface finish. Although there is a slight difference in surface response value however these were treated equal for analysis. Experiments were repeated using the $\mathrm{N}_{2}$ gas and surface finish compared with already available results as given in Table 5 and Fig. 6.

Nearly common values of surface finish for dry, conventional and cryogenic conditions were selected as given in Table 6.

Now calculated the cutting power, cutting time and material removal rates against each individual response value. For cutting power the equation used given in [23]:
$P_{c}=\frac{a_{p} \cdot a_{e} \cdot v_{f} \cdot K_{c}}{60 \times 10^{6}}$

Where $a_{p}$ is depth of cut (mm), $a_{e}$ is cutting width $(\mathrm{mm}), v_{f}$ is table feed per $\min (\mathrm{mm} / \mathrm{min})$ and $\mathrm{K}_{\mathrm{c}}$ is specific cutting force $\left(\mathrm{N} / \mathrm{mm}^{2}\right)$. Taking specific cutting force as $3000 \mathrm{~N} / \mathrm{mm}^{2}$ for Titanium. Cutting time calculated by dividing cutting

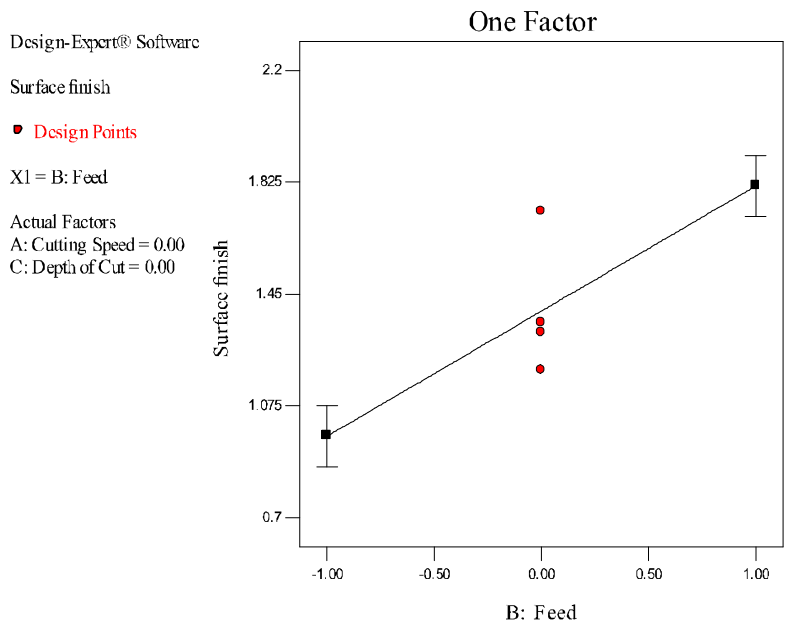

FIG. 5. EFFECT OF FEED CHANGE OVER THE SURFACE FINISH

TABLE 4. ANOVA FOR RESPONSE SURFACE MODEL

\begin{tabular}{|c|c|c|c|c|c|c|}
\hline Source & Sum of Squares & Df & Mean Square & F-Value & $\begin{array}{c}\text { P-value } \\
\text { Prob }>\text { F }\end{array}$ & Significant \\
\hline Model & 2.94 & 3 & 0.98 & 28.33 & $<0.0001$ \\
\hline (a) Cuttig Speed & 0.16 & 1 & 0.16 & 4.71 & 0.0477 \\
\hline (b) Feed & 2.40 & 1 & 2.40 & 69.36 & $<0.0001$ \\
\hline (c) Depth of Cut & 0.38 & 1 & 0.38 & 10.91 & 0.0052 \\
\hline Residual & 0.48 & 14 & 0.035 & & 0.7884 \\
\hline Lack of fit & 0.33 & 11 & & 0.030 & 0.57 & Significant \\
\hline Pure error & 0.16 & 3 & & 0.052 & & \\
\hline Cor total & 3.42 & 17 & & & & \\
\hline R-Squared & 0.8586 & Standard Deviation & 0.19 & CV $\%$ & 13.35 & Pred R-Squared \\
\hline Adj R-Squared & 0.8282 & Mean & 1.39 & PRESS & 0.79 & Adeq Precision \\
\hline
\end{tabular}

Mehran University Research Journal of Engineering \& Technology, Volume 36, No. 2, April, 2017 [p-ISSN: 0254-7821, e-ISSN: 2413-7219] 
length (taken as $100 \mathrm{~mm}$ ) with the respective cutting speed. MRR (Material Removal Rates) were calculated by multiplying the cutting speed, feed and depth of cut at respective response values and results quoted in Table 7.

\section{4. $\quad$ RESULT ANALYSIS AND DISCUSSION}

As shown by graph in Figs. 7-8, it is clear that cutting power is less for dry machining up to a certain limit of surface finish i.e. below $1 \mu \mathrm{m}$ and it is higher for conventional machining for above $1 \mu \mathrm{m}$. In dry machining the coolant pump does not work while power is consumed in the pumping of coolant for conventional machining which ultimately becomes higher in value as compared to dry. Therefore total energy required will become higher in conventional as compared to dry. Cryogenic machining requires less energy for chip removal process as compared with dry and conventional.

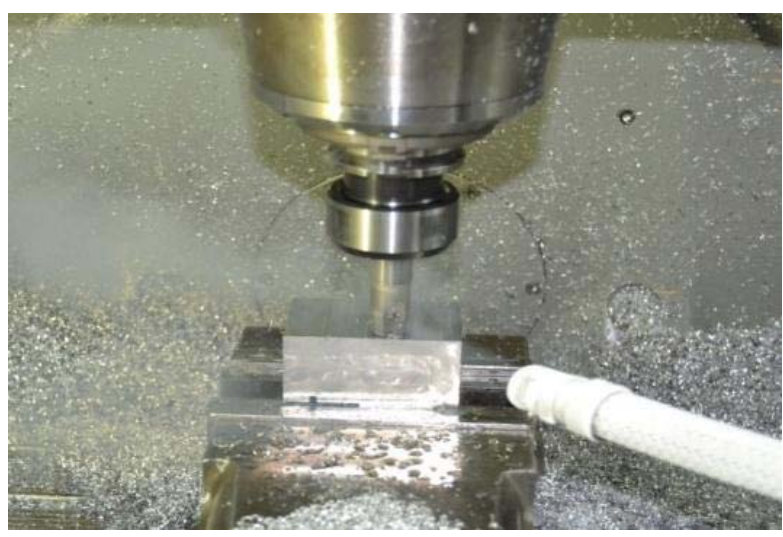

FIG. 6. CRYOGENIC MACHINING

TABLE 5. SURFACE FINISH RESPONSE FOR DRY, CONVENTIONAL AND CRYOGENIC MACHINING

\begin{tabular}{|c|c|c|c|c|c|c|c|}
\hline \multirow{2}{*}{ No. } & \multicolumn{2}{|c|}{ Cutting Speed } & \multirow{2}{*}{$\begin{array}{c}\text { Feed } \\
\text { (mm/tooth) }\end{array}$} & \multirow{2}{*}{$\begin{array}{l}\text { Depth of Cut } \\
\quad(\mathrm{mm})\end{array}$} & \multicolumn{3}{|c|}{ Surface Finish $(\mu \mathrm{m})$} \\
\hline & RPM & $\mathrm{mm} / \mathrm{min}$ & & & Dry & Conventional & Cryogenic \\
\hline 1. & 318.310 & 63.662 & 0.1 & 0.050 & 0.89 & 1.996 & 0.519 \\
\hline 2. & 795.775 & 159.155 & 0.1 & 0.050 & 0.95 & 1.98 & 0.569 \\
\hline 3. & 318.310 & 127.324 & 0.2 & 0.050 & 1.62 & 0.929 & 0.5 \\
\hline 4. & 795.775 & 318.310 & 0.2 & 0.050 & 1.77 & 0.587 & 0.684 \\
\hline 5. & 318.310 & 63.662 & 0.1 & 0.150 & 1.043 & 0.289 & 0.37 \\
\hline 6. & 795.775 & 159.155 & 0.1 & 0.150 & 1.073 & 0.431 & 0.339 \\
\hline 7. & 318.310 & 127.324 & 0.2 & 0.150 & 2.151 & 0.853 & 0.63 \\
\hline 8. & 795.775 & 318.310 & 0.2 & 0.150 & 2.198 & 0.929 & 0.557 \\
\hline 9. & 155.542 & 46.663 & 0.15 & 0.100 & 0.894 & 1.019 & 1.447 \\
\hline 10. & 958.542 & 287.563 & 0.15 & 0.100 & 1.61 & 1.578 & 1.5 \\
\hline 11. & 557.042 & 73.530 & 0.066 & 0.100 & 0.763 & 0.681 & 0.362 \\
\hline 12. & 557.042 & 260.696 & 0.234 & 0.100 & 1.916 & 2.738 & 2.348 \\
\hline 13. & 557.042 & 167.113 & 0.15 & 0.016 & 0.991 & 1.187 & 0.63 \\
\hline 14. & 557.042 & 167.113 & 0.15 & 0.184 & 1.606 & 1.823 & 0.905 \\
\hline 15. & 557.042 & 167.113 & 0.15 & 0.100 & 1.727 & 1.078 & 0.947 \\
\hline 16. & 557.042 & 167.113 & 0.15 & 0.100 & 1.321 & 1.349 & 0.383 \\
\hline 17. & 557.042 & 167.113 & 0.15 & 0.100 & 1.354 & 1.188 & 0.3 \\
\hline 18. & 557.042 & 167.113 & 0.15 & 0.100 & 1.195 & 1.301 & 0.447 \\
\hline 19. & 557.042 & 167.113 & 0.15 & 0.100 & - & 1.02 & 0.946 \\
\hline 20. & 557.042 & 167.113 & 0.15 & 0.100 & - & 0.98 & 0.975 \\
\hline
\end{tabular}


As shown in Figs. 9-10, cutting time for cryogenic machining is less from both dry and conventional. For $5^{\text {th }}$ iteration the response value given is 1.447 which is quite greater than the respective values of dry and conventional (i.e. 1.195 and 1.187). Therefore its effect can be neglected.

Results compared for nearly same output of surface finish in each of the processes. Overall energy consumption for conventional cooling will include energy of pumping coolant. Hence it will become higher than cryogenic.

TABLE 6. SELECTED RESPONSE VALUES

\begin{tabular}{|c|c|c|c|}
\hline No. & Dry & Conventional & Cryogenic \\
\hline 1. & 0.89 & 0.853 & 0.905 \\
\hline 2. & 0.95 & 0.929 & 0.947 \\
\hline 3. & 1.043 & 1.019 & 0.946 \\
\hline 4. & 1.073 & 1.078 & 0.975 \\
\hline 5. & 1.195 & 1.187 & 1.447 \\
\hline 6. & 1.354 & 1.349 & 1.5 \\
\hline
\end{tabular}

As the tool wear is more in dry machining, the time of tool change will also be added affecting the increase in overall machining time. Average cutting time for conventional machining is already greater than cryogenic.

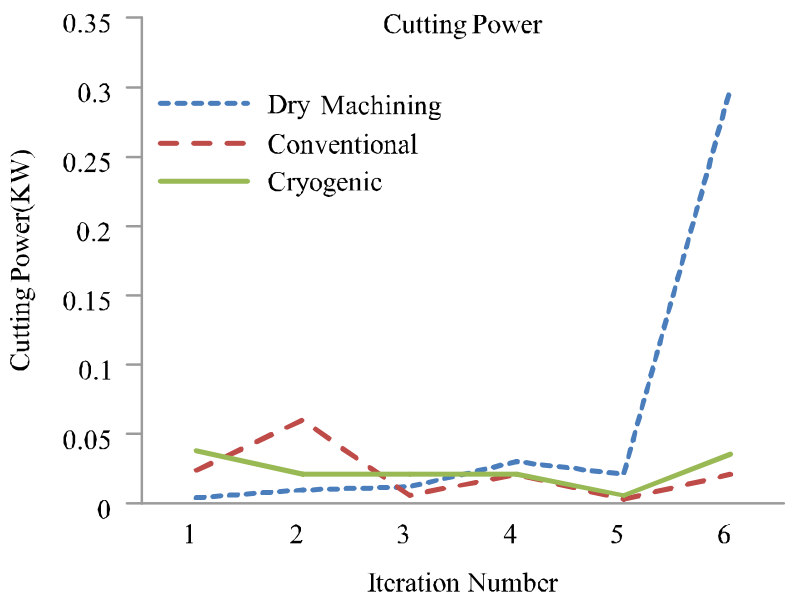

FIG. 7. CUTTING POWER COMPARISON

TABLE 7. CUTTING POWER, CUTTING TIME AND MRR FOR SELECTED RESPONSE

\begin{tabular}{|c|c|c|c|c|}
\hline Parameter & Iteration No. & Dry Machining & Conventional & Cryogenic \\
\hline \multirow{6}{*}{ Cutting Power (KW) } & 1 & 0.004 & 0.024 & 0.038 \\
\hline & 2 & 0.010 & 0.060 & 0.021 \\
\hline & 3 & 0.012 & 0.006 & 0.021 \\
\hline & 4 & 0.030 & 0.021 & 0.021 \\
\hline & 5 & 0.021 & 0.003 & 0.006 \\
\hline & 6 & 0.3 & 0.021 & 0.036 \\
\hline \multirow{6}{*}{$\begin{array}{l}\text { Cutting Time }(\min )=\text { Cutting } \\
\text { Length/Cutting Speed }\end{array}$} & 1 & 1.571 & 0.785 & 0.598 \\
\hline & 2 & 0.785 & 0.314 & 0.598 \\
\hline & 3 & 1.571 & 2.143 & 0.598 \\
\hline & 4 & 0.628 & 0.598 & 0.598 \\
\hline & 5 & 0.598 & 0.598 & 2.143 \\
\hline & 6 & 0.598 & 0.598 & 0.348 \\
\hline \multirow{6}{*}{$\begin{array}{c}\text { MRR }\left(\mathrm{mm}^{3} / \mathrm{min}\right)=\text { Cutting Speed } \times \text { Feed } \\
\text { x Depth of Cut }\end{array}$} & 1 & 0.318 & 3.820 & 4.612 \\
\hline & 2 & 0.796 & 9.549 & 2.507 \\
\hline & 3 & 0.955 & 0.700 & 2.507 \\
\hline & 4 & 2.387 & 2.507 & 2.507 \\
\hline & 5 & 2.507 & 0.401 & 0.700 \\
\hline & 6 & 2.507 & 2.507 & 4.313 \\
\hline
\end{tabular}

Mehran University Research Journal of Engineering \& Technology, Volume 36, No. 2, April, 2017 [p-ISSN: 0254-7821, e-ISSN: 2413-7219] 
In getting nearly same results of surface finish, it is shown in Fig. 11 that more material is removed in cryogenic as compared to the dry and conventional. Average MRR for nearly similar response values were calculated and compared as shown in Fig. 12. It was found that MRR is more for cryogenic and conventional as compared with dry machining. It results in high production rate.

\section{SUSTAINABILITY ASSESSMENT}

Sustainability of a machining process refers to the impact on environment, power consumption and safe for operator [24], which were satisfied in the experimental works as the cost of tool was reduced in the cryogenic cooling and it also impact on time saving for tool changing and setup time, which results in increasing productivity. An

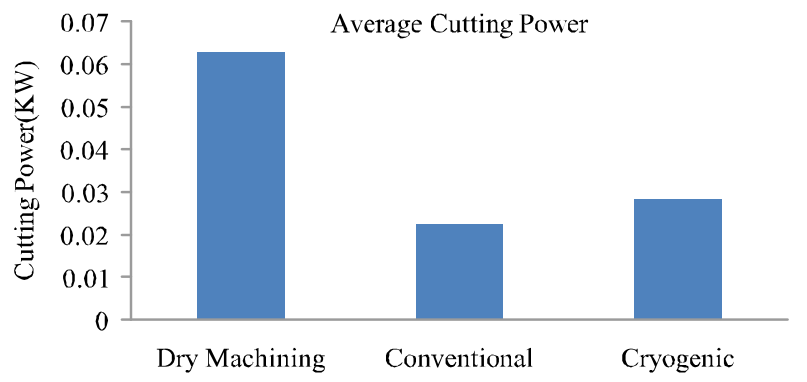

FIG. 8 AVERAGE CUTTING POWER COMPARISON

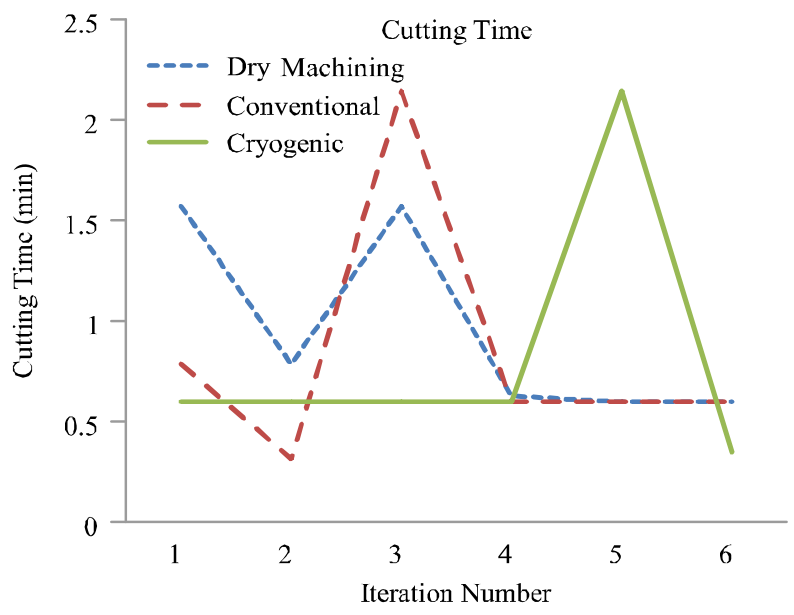

FIG. 9. CUTTING TIME COMPARISON advantage of cutting in cryogenic process is evaporating back of cooling gas into air which ensures the healthy environment for workers.

Effective cutting power, cutting time and MRR were found lowest for cryogenic machining when considering the

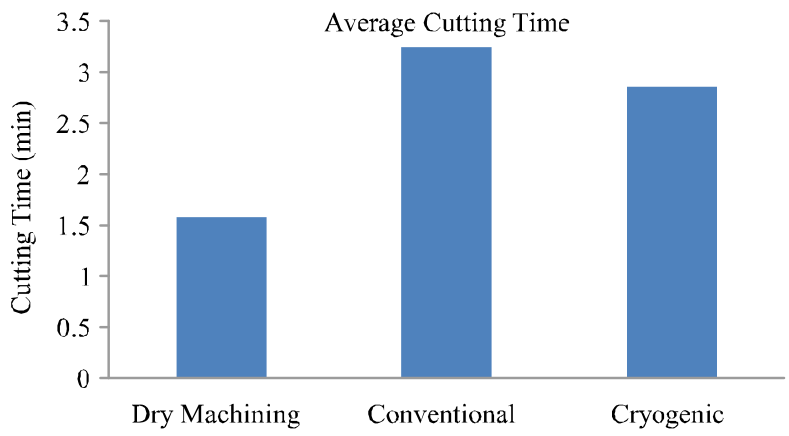

FIG. 10. AVERAGE CUTTING TIME COMPARISON

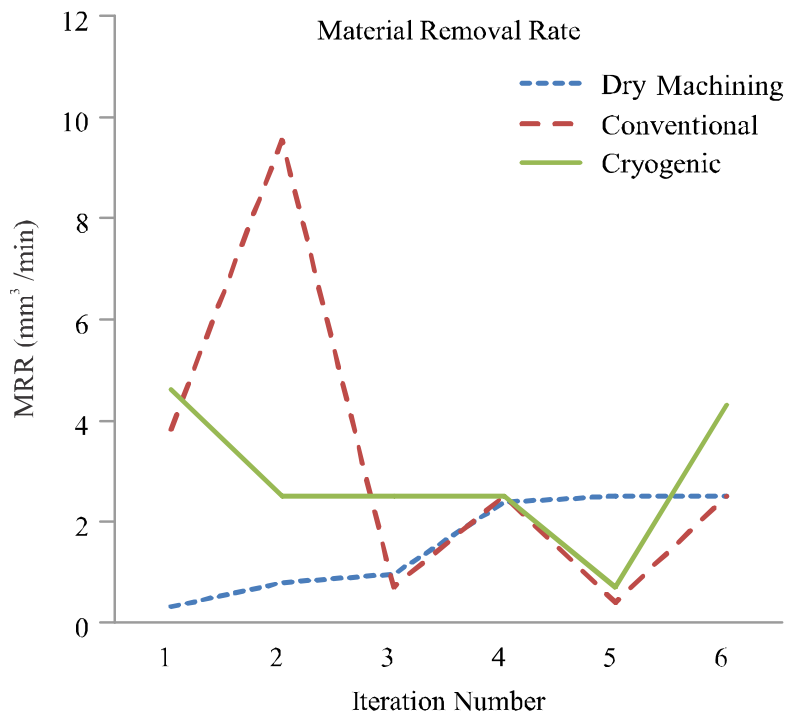

FIG. 11. MRR COMPARISON

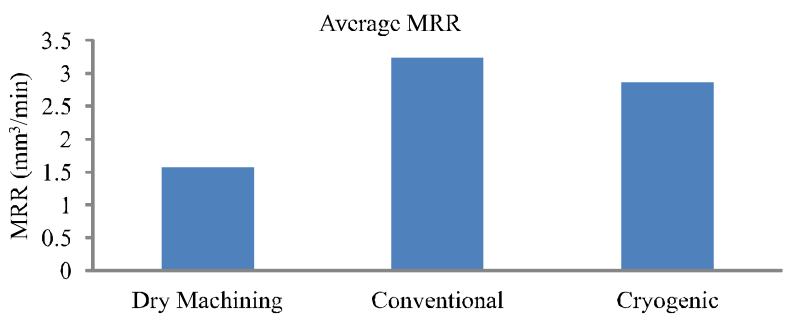

FIG. 12. AVERAGE MRR COMPARISON FOR DRY, CONVENTIONAL AND CRYOGENIC COOLING

Mehran University Research Journal of Engineering \& Technology, Volume 36, No. 2, April, 2017 [p-ISSN: 0254-7821, e-ISSN: 2413-7219] 
power of coolant pump for conventional machining and cutting tool wear for dry machining. As a result it is found that cryogenic machining is more sustainable than conventional and dry machining of face milling of titanium Ti-6Al-4V.

Cryogenic cooling is much more important to ensure the sustainability and most effective in getting fine surface finish in milling as compared to other cooling techniques. As shown in Figs. 13-14 fine surface finish is obtained in cryogenic machining with less material wastage, energy requirements for cutting material and time for machining. Resulting that cryogenic machining meets the sustainable machining requirements.

Cutting tool wear observed more in dry machining. Less wear was observed in cutting using coolant and no wear was observed while machining using Nitrogen gas as coolant (Figs. 15-17).

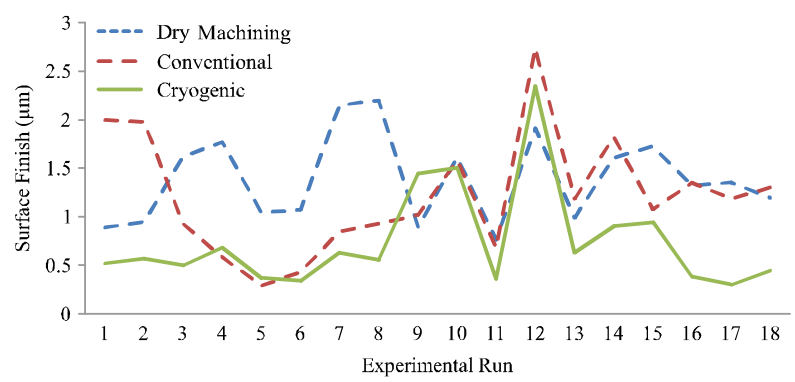

FIG. 13. SURFACE FINISH COMPARISON

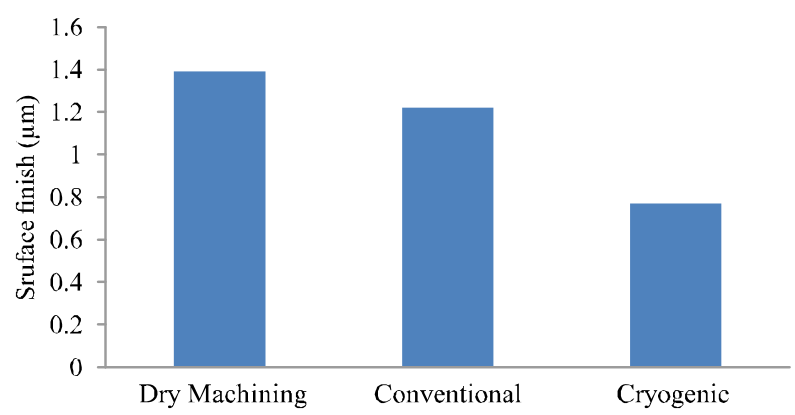

FIG. 14. AVERAGE SURFACE FINISH COMPARISON

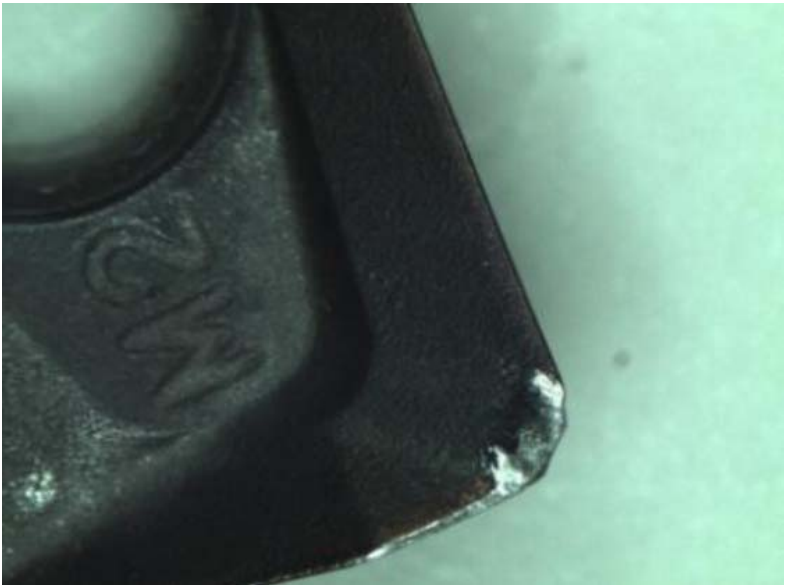

FIG. 15. TOOL WEAR IN DRY MACHINING

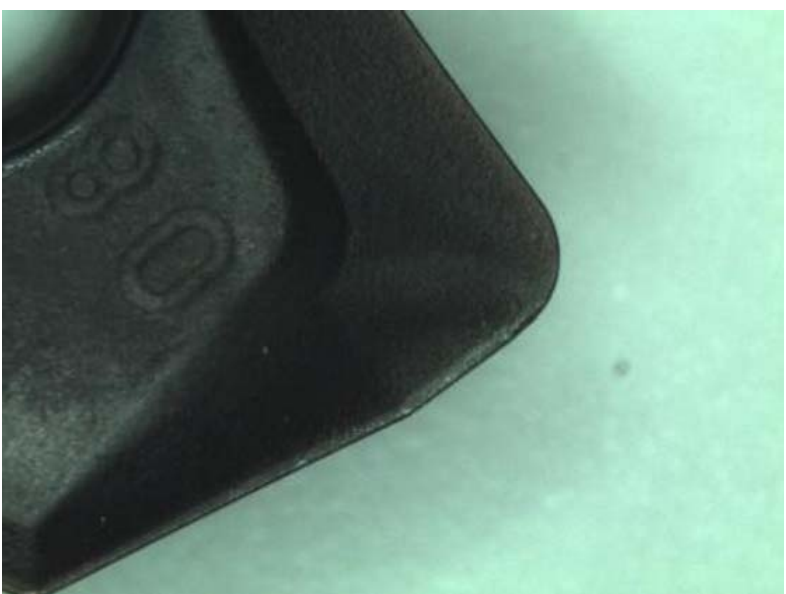

FIG. 16. TOOL WEAR USING COOLANT

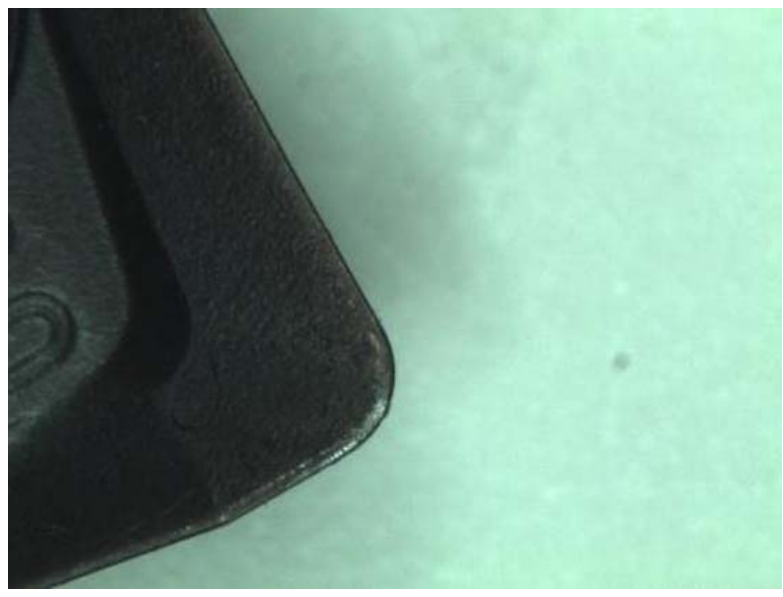

FIG. 17. TOOL WEAR IN CRYOGENIC MACHINING

Mehran University Research Journal of Engineering \& Technology, Volume 36, No. 2, April, 2017 [p-ISSN: 0254-7821, e-ISSN: 2413-7219] 


\section{CONCLUSIONS}

Minimum value of surface finish was obtained by the cryogenic machining using the coated carbide cutting tools. The cutting tool was not damaged by cryogenic cooling ensuring both the sustainability and cost saving. Effect of feed, speed and depth of cut on the surface finish is summarized. $\mathrm{R}_{\mathrm{a}}$ is significantly changed with change in feed whereas $\mathrm{R}_{\mathrm{a}}$ is less significantly changed with variation of speed and depth of cut.

From the experimental results it is concluded that cryogenic machining is recommended for difficult-tomachine materials and super alloys. Results are satisfying sustainability for negative impact on environment, reduced tooling and energy cost. Efforts can be made to switch from conventional machining to cryogenic machining which would be beneficial in reducing machining costs, health risks with getting fine surface finish.

\section{ACKNOWLEDGEMENTS}

The Authors offer the gratitude to colleagues and competent authorities for their assistance in material arrangement, experimentation, testing facility provision and other technical guidance for completion of this research work.

\section{REFERENCES}

[1] Zhai, Y., and Dornfeld, "A Three Dimensional System Approach for Environmentally Sustainable Manufacturing", CIRP Annals-Manufacturing Technology, Volume 61, pp. 39-42, France, 2012.

[2] Yoshikawa, J., Boër, A., and Williams, W., "The Incoming Global Technological and Industrial Revolution Towards Competitive Sustainable Manufacturing", CIRP Annals-Manufacturing Technology, Volume 57, pp. 641-659, France, 2008.

[3] Lee and Badrul, "Optimization for Sustainable Manufacturing Based on Axiomatic Design Principles: A case Study of Machining Processes", Advances in Production Engineering \& Management, Volume 9, pp. 31-43, Slovenia, 2014.
[4] Hesselbach, H., Öhlschläger, B.Z., and Dettmer, "Ecologically Benign Lubricants-Evaluation from a Life Cycle Perspective", CLEAN-Soil, Air, Water, Volume 35, pp. 427-432, Germany, 2007.

[5] Inasaki, S.W., and Wakabayashi, "Dry Machining and Minimum Quantity Lubrication”, CIRP AnnalsManufacturing Technology, Volume 53, pp. 511-537, France, 2004.

[6] Kopac, and Pusavec, "Sustainability Spirit in Manufacturing/Machining Processes", International Conference on Management of Engineering \& Technology, PICMET., pp. 1197-1205, USA, 2009.

[7] Westkämper, "Manufuture and Sustainable Manufacturing", Manufacturing Systems and Technologies for the New Frontier, Springer, pp. 11-14, Japan, 2008.

[8] Ezugwu, "Key Improvements in the Machining of Difficult-to-Cut Aerospace Superalloys", International Journal of Machine Tools and Manufacture, Volume 45, pp. 1353-1367, UK, 2005.

[9] Deshpande, P., Kopaè, M.D., and Jawahir, "Modeling and Optimization of Machining of High Temperature Nickel Alloy for Improved Machining Performance and Enhanced Sustainability", Proceedings of 11th CIRP Conference on Modeling of Machining Operations, USA, 2008.

[10] Devillez, D., Larrouquere, M.Z., and Vigneau, "A Review of Developments Towards Dry and High Speed Machining of Inconel 718 Alloy”, International Journal of Machine Tools and Manufacture, Volume 44, pp. 439-456, UK, 2004.

[11] Ezugwu, and Bonney, "Effect of High-Pressure Coolant Supply when Machining Nickel-Base, Inconel 718, Alloy with Coated Carbide Tools", Journal of Materials Processing Technology, Volume 153, pp. 1045-1050, Germany, 2004.

[12] Kramar, and Kopac, "High Performance Manufacturing Aspect of Hard-to-Machine Materials", Journal of Advances in Production Engineering \& Management, Volume 1, p. 2, Slovenia, 2009.

[13] Li, S.E., Iqbal, and Xiao, X., "Refrigerated Cooling Air Cutting of Difficult-to-Cut Materials", International Journal of Machine Tools and Manufacture, Volume 47, pp. 927-933, UK, 2007. 
[14] Marksberry, "Micro-Flood (MF) Technology for Sustainable Manufacturing Operations that are Coolant Less and Occupationally Friendly", Journal of Cleaner Production, Volume 15, pp. 958-971, Netherlands, 2007.

[15] Marksberry, “An Assessment of Tool-Life Performance in NDM (Near Dry Machining) for Sustainable Manufacturing of Automotive Steel Components", Dissertation, Department of Mechanical Engineering, College of Engineering, University of Kentucky, USA, 2004 .

[16] Yan, Y., and Liu, "Influence of Minimum Quantity Lubrication Parameters on Tool Wear and Surface Roughness in Milling of Forged Steel", Chinese Journal of Mechanical Engineering, Volume 25, pp. 419-429, China, 2012.

[17] Yildiz, and Nalbant, "A Review of Cryogenic Cooling in Machining Processes", International Journal of Machine Tools and Manufacture, Volume 48, pp. 947-964, UK, 2008 .

[18] Jawahir, and Dillon, "Sustainable Manufacturing Processes: New Challenges for Developing Predictive Models and Optimization Techniques", Proceedings of $1^{\text {st }}$ International Conference on Sustainable Manufacturing, pp. 1-19, Canada, 2007
Ghosh, Z., and Frey, "Cryogenic Machining with Brittle Tools and Effects on Tool Life", ASME International Mechanical Engineering Congress and Exposition, pp. 201-209, USA, 2003

[20] Khan, D.K., and Chattopadhyay, "Effects of Cryogenic Cooling by Liquid Nitrogen Jets on Tool Wear, Surface Finish and Dimensional Deviation in Turning Different Steels", International Journal of Machining and Machinability of Materials, Volume 1, pp. 115-131, Portugal, 2006.

[21] Silva, D., Machado, F.E., and Souza, Jr., "Performance of Cryogenically Treated HSS Tools", Wear, Volume 261, pp. 674-685, USA, 2006.

[22] Cus, and Balic, "Optimization of Cutting Process by GA Approach", Robotics and Computer-Integrated Manufacturing, Volume 19, pp. 113-121, USA, 2003.

[23] Olteanu, Bisu, and Tanase, "Determination of Power Consumption in Milling," Scientific Bulletin, Series-D, University Politehnica of Bucharest. pp. 211-220, Romania,2013.

[24] Aramcharoen, and Chuan, “An Experimental Investigation on Cryogenic Milling of Inconel 718 and its Sustainability Assessment", Procedia CIRP, Volume 14, pp. 529-534, France, 2014. 